\title{
Escape-Route Planning of Underground Coal Mine Based on Improved Ant Algorithm
}

\author{
Guangwei Yan and Dandan Feng \\ School of Control and Computer Engineering, North China Electric Power University, \\ Beijing 102206, China \\ Correspondence should be addressed to Guangwei Yan; yan_guang_wei@126.com
}

Received 2 October 2012; Revised 1 December 2012; Accepted 4 December 2012

Academic Editor: Baozhen Yao

Copyright (c) 2013 G. Yan and D. Feng. This is an open access article distributed under the Creative Commons Attribution License, which permits unrestricted use, distribution, and reproduction in any medium, provided the original work is properly cited.

\begin{abstract}
When a mine disaster occurs, to lessen disaster losses and improve survival chances of the trapped miners, good escape routes need to be found and used. Based on the improved ant algorithm, we proposed a new escape-route planning method of underground mines. At first, six factors which influence escape difficulty are evaluated and a weight calculation model is built to form a weighted graph of the underground tunnels. Then an improved ant algorithm is designed and used to find good escape routes. We proposed a tunnel network zoning method to improve the searching efficiency of the ant algorithm. We use max-min ant system method to optimize the meeting strategy of ants and improve the performance of the ant algorithm. In addition, when a small part of the mine tunnel network changes, the system may fix the optimal routes and avoid starting a new processing procedure. Experiments show that the proposed method can find good escape routes efficiently and can be used in the escape-route planning of large and medium underground coal mines.
\end{abstract}

\section{Introduction}

In mining, water, fire, gas, and other natural disasters often occur. The disasters have a heavy effect to mines' safety production. Statistics show the coal mine industry has the most serious casualty accidents in China [1]. From 1991 to 2001, 86000 people died in coal mine accident, accounts for $85 \%$ of deaths in the mining industry. According to statistics in 2006-2008, in high-risk industries of China, the proportion of coal mine accidents and deaths equal $21.3 \%$ and $28.5 \%$, respectively, top the list of industrial and mining business enterprises [2].

When mine disaster occurs, it is very important to find good escape routes. Escape routes planning can be realized based on computers, sensor networks, and relevant data. This problem had been studied at home and abroad, literature [3-7] use the Dijkstra algorithm or its improved algorithm to solve the problem. These algorithms are different in time complexity, space complexity, and so forth. The Dijkstra algorithm has three shortages. First, large amounts of calculation are required when number of network nodes and edges reaches several hundred, because these algorithms usually need to traverse all vertices of the network. Second, the Dijkstra algorithm only obtains the best route and in fact the second-best route is needed sometimes. Third, the Dijkstra algorithm is static, if mine states change, it needs to be recalculated.

Put forward by Italian scholar Dorigo et al., the ant algorithm [8] is a new heuristic evolutionary algorithm. Biological ant colony can produce a chemical substance called pheromone for communication and coordination of ants. Pheromone can form positive feedback and make individual ants gradually gathered in the shortest route between the food source and the nest. The algorithm has advantages of strong robustness, distributed computing, positive feedback mechanism and it is easy to combine with other algorithms. When solving the shortest route in large-scale network, it has excellent feasibility and adaptability.

In this paper, factors which influence passing difficulty in tunnels are led into. Based on these factors and the actual lengths of the tunnels, equivalent lengths of the tunnels are calculated and acted as weights of the underground tunnel graph. This graph acts as the input of the improved ant algorithm. 


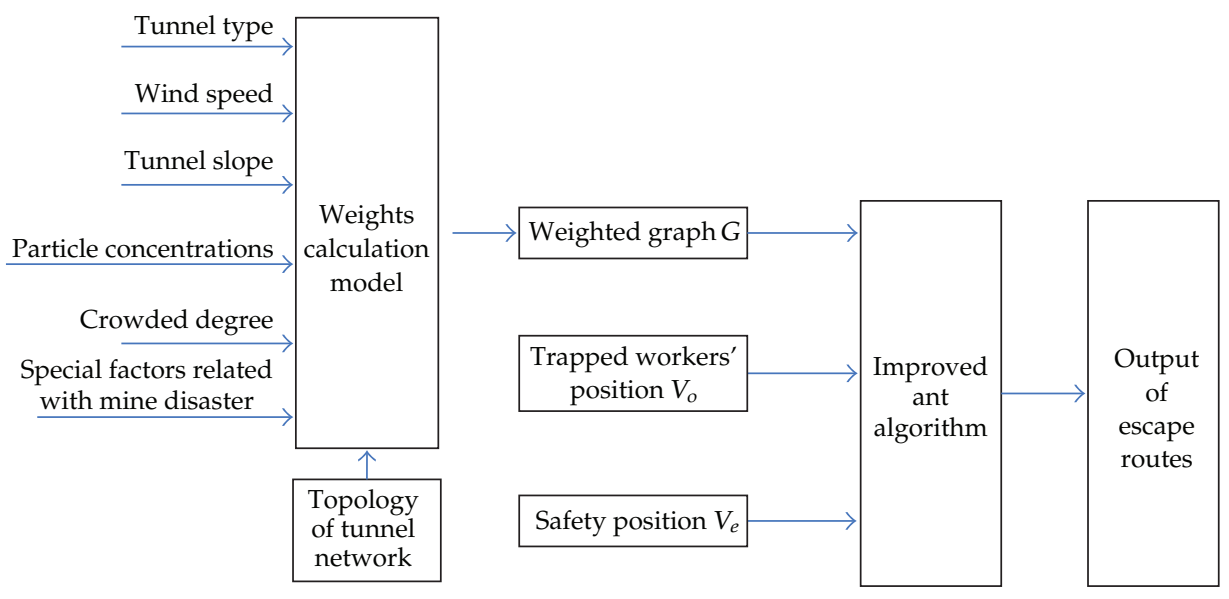

FIGURE 1: System Framework.

In this paper, an important improvement to the ant algorithm is introducing tunnel zoning. Underground mine networks include many faces and main tunnels. This paper divides all mine zones into two types: the backbone-zone $S_{0}$ and the nonbackbone-zone $S_{n}(n=1,2,3 \ldots)$. The backbonezone $S_{0}$ is the main searching area, containing backbone tunnels and the safety point. The nonbackbone-zone $S_{n}$ containing several zones, each face is a nonbackbone-zone. They connect to the main road (See Figure 2). By zoning the weighted graph of tunnels, the ants' behaviors can be affected and the searching efficiency can be improved.

The experimental results in this paper show the improved algorithm are suitable for escape routes planning of large and medium sized mines.

\section{System Framework}

To calculate the optimal escape routes in underground mines, tunnels' status and data should be provided. And these can be obtained by sensor network in tunnels. In different mine disasters, factors that influence men passing difficulty of the tunnel are various and complex. Based on methods proposed by literature $[9,10]$, these factors are generalized for six classes including tunnel type, wind speed, tunnel slope, particle concentrations, crowded degree, and special factors related with mine disaster. Firstly, these factors are converted to tunnel equivalent length according to the formula (1). Secondly, a graph denoted by $G(V, E)$ is built based on the tunnel network topology and the normalized tunnel equivalent lengths which act as the graph weights. Thirdly, a group of underground workers is set as node $V_{0}$ and a safety point or exit point is set as $V_{e}$ in $G$. Finally, improved ant algorithm is used to plan the optimal route and several alternative routes between the terminals $\left(V_{0}, V_{e}\right)$ in $G$. The system implementation framework is shown in Figure 1.

\section{Calculation of Tunnel Weights}

3.1. Calculation of Tunnel Equivalent Length. Status of underground tunnels are various and complex. Factors influencing passing difficulty of tunnels are generalized for six classes including tunnel type, wind speed, tunnel slope, particle concentrations, crowded degree, and special factors related to mine disasters. These factors influence people's escape speed and they can increase or decrease the escape speed $v$. The influences of these factors to the escape speed $v$ are transformed to the tunnels' equivalent length. The smaller the value of the speed $v$ is, the longer the tunnel equivalent length is and vice versa. Formula (1) gives the calculation method of the tunnel equivalent lengths. And these equivalent lengths are as weights of the graph $G$ after normalizing:

$$
l_{i}=\left(k_{t i} \cdot k_{w i} \cdot k_{g i} \cdot k_{v i} \cdot k_{m i} \cdot k_{d i}\right) l_{r i}
$$

In (1), $l_{r i}$ indicates the actual length of the tunnel $i$ and $l_{i}$ is the equivalent length of the tunnel $i ; k_{t i}, k_{w i}, k_{g i}, k_{v i}, k_{m i}, k_{d i}$ are tunnel type influence coefficient, tunnel wind speed influence coefficient, tunnel slope influence coefficient, tunnel particle concentrations influence coefficient, tunnel crowded degree influence coefficient, special factors related to mine disasters influence coefficient of the tunnel $i$, respectively. Below we explain the relationship of these coefficients and the escape speed $v$.

We denote the people's normal walking speed by $v_{0}$. Under the influence of the tunnel type coefficient, the people escape speed $v$ equals to $v_{0} / k_{t i}$. These six coefficients are independent, and under their common influence, the escape speed $v$ equals to $v_{0} /\left(k_{t i} \cdot k_{w i} \cdot k_{g i} \cdot k_{v i} \cdot k_{m i} \cdot k_{d i}\right)$. Through formula (1), we can know the escape time $t$ (which equals to $l_{r i} / v$ ) also equals to $l_{i} / v_{0}$. Below we will explain in detail how these coefficients are calculated and how they influence the escape speed $v$ separately.

3.1.1. Tunnel Type Influence Coefficient. Underground tunnels can generally be divided into working surface, transport tape lane, contact lane, rail lane, shaft, air leakage branch, and ventilation borehole, in which the air leakage branch and the ventilation borehole are forbidden for people to pass. Tunnel type may influence the people's escape speed. For example, in the rail lane, the passing speed is equal to the speed of 


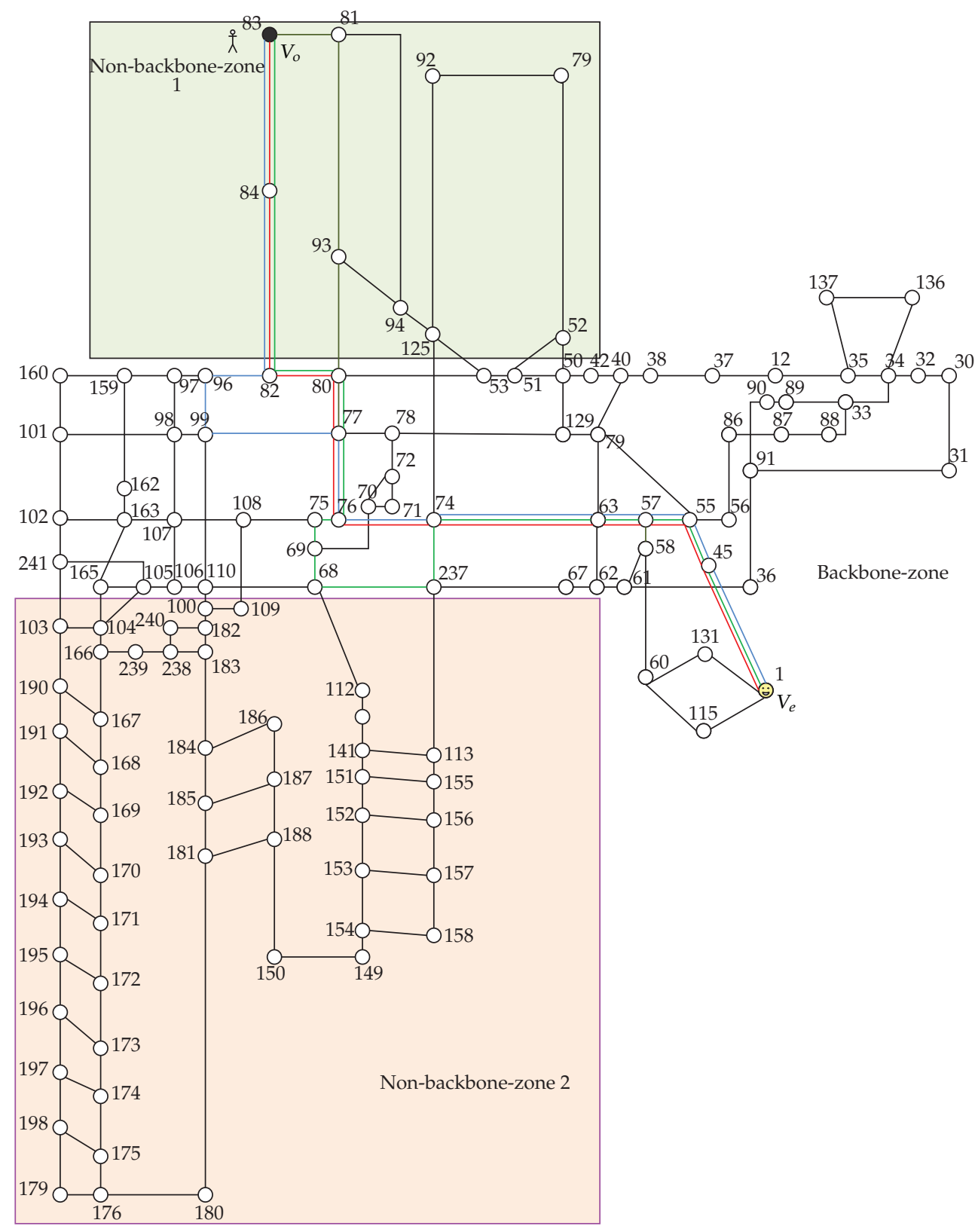

FIGURE 2: The network topology of the mine.

transportation tool. Formula (2) gives the calculating method of the tunnel type influence coefficient.

$$
k_{t i}= \begin{cases}\frac{v_{0}}{v_{\text {vehicle }},} & \text { tunnel } i \text { is the rail lane type, } \\ +\infty, & \text { tunnel } i \text { is the air leakage branch } \\ & \text { or the ventilation borehole type } \\ 1, & \text { other tunnel type. }\end{cases}
$$

The parameter $v_{\text {vehicle }}$ represents the speed of the transformation tool. People's moving speed equals to the speed of the vehicle when people are in the vehicle. When the value of $v_{\text {vehicle }}$ is greater than the value of $v_{0}$, the value of $k_{t i}$ is smaller than 1 . And this indicates the equivalent length of the tunnel $i$ will decrease according to the formula (1) and the people will spend less time to pass through the tunnel.

3.1.2. Wind Speed Influence Coefficient. The mine networks is a thorough ventilation system itself. Generally in the total return lanes the wind speed is big. The wind speed may influence people's escape speed.

It influence degree is in direct ratio with the actual roadway length. We assume the human's walking power is constant and denote it by $P_{0}$, and only taking stable states into account, we can derive the formula under against wind situation as follows:

$$
P_{0}=F v_{0}=\left(F+F_{w}\right) v
$$


where $F$ is the power of the humanand $v_{0}$ is the normal human walking speed without any outside influence. And $F_{w}$ is the power of wind and $v$ is the human's speed after affected by wind.

Assume the person is a cuboid object, and $F_{w}$ can be derived from the Bernoulli's equation [11]:

$$
F_{w}=\frac{c_{d} \rho S v_{w}^{2}}{2}
$$

The parameter $c_{d}$ is a resistance coefficient, experience shows that it is related to the Reynolds number; $\rho$ is the density of the gas; $S$ is the touching surface area between the human body and the wind; $v_{w}$ is the wind speed in the current roadway.

This paper concludes (5) from (3) and (4):

$$
v=\frac{2 v_{0} P_{0}}{2 P_{0}+c_{d} \rho S v_{0} v_{w}^{2}} .
$$

The wind speed influence coefficient under against wind situation is shown as

$$
k_{w i}=\frac{l_{i}}{l_{r i}}=\frac{v_{0}}{v}=\frac{2 P_{0}+c_{d} \rho S v_{0} v_{w}^{2}}{2 P_{0}} .
$$

Similarly, the coefficient under following wind situation is shown as follows:

$$
k_{w i}=\frac{2 P_{0}-c_{d} \rho S v_{0} v_{w}^{2}}{2 P_{0}} .
$$

Formula (7) has a limitation: when the wind speed is too big, this formula is not applicable.

3.1.3. Tunnel Slope Influence Coefficient. Tunnel gradient influences the peoples' walking speed. The greater the slope is, the greater the resistance is. With the same analysis method as Section 3.1.2, we get the formula as follows under climbing situation:

$$
P_{0}=F v_{0}=m g v \sin \theta_{i}+F v \cos \theta_{i},
$$

where $m$ is the standard human mass, $g$ is the gravity acceleration, $\theta_{i}$ is the current tunnel's angle of slope. The tunnel upslope influence coefficient can be represented as follows:

$$
k_{g i}=\frac{v_{0}}{v}=\frac{m g v_{0} \sin \theta_{i}}{P_{0}}+\cos \theta_{i}
$$

When workers pass down slope tunnels, we assume their speed will still be $v_{0}$ (i.e., $k_{g i}=1$ ).

The parameter values in Sections 3.1.2 and 3.1.3 are shown in Table 1.

\subsubsection{Tunnel Particle Concentrations Influence Coefficient.} Tunnel particle concentrations mainly include tunnel visibility, the height between the gas critical layer and the floor. They have important effects on the walking speed of people who
TABle 1: Parameters' values.

\begin{tabular}{lc}
\hline Parameter name & Value \\
\hline$\rho$ & $1.2\left(\mathrm{~kg} / \mathrm{m}^{3}\right)$ \\
$S$ & $0.7225\left(\mathrm{~m}^{2}\right)$ \\
$c_{d}$ & 0.8 \\
$P_{0}$ & $200(\mathrm{w})$ \\
$m$ & $80(\mathrm{~kg})$ \\
$v_{0}$ & $5(\mathrm{~m} / \mathrm{s})$ \\
\hline
\end{tabular}

are escaping [12]. This coefficient is denoted by $k_{v i}$, and its calculation method is

$$
k_{v i}=\left(1+\alpha_{h}+L_{r}\right) .
$$

In (10), $\alpha_{h}$ is the effecting coefficient of the height of gas layer and its empirical value is shown in Table 2 [12]; $L_{r}$ is the affecting coefficient of visibility; its empirical value is shown in Table 3.

3.1.5. Tunnel Crowded Degree. The denseness of the crowd affects the walking speed to some extent. Thompson proposed a speed calculation method which utilized the crowd denseness factor in Simulex model [13]. This method can be expressed as a coefficient calculation formula as follows:

$$
k_{m i}= \begin{cases}\frac{1}{\sin \left\{90^{\circ} \times\left((d-b) /\left(t_{d}-b\right)\right)\right\}}, & b<d<t_{d}, \\ 1, & d \geq t_{d} .\end{cases}
$$

In (11), $d$ represents the body interval between people, here the body interval means the distance from one person's body center to another person's body center (we assume the people have the same height); $t_{d}$ represents the upper limit of the moving constraint interval; $b$ represents the size of the body in horizontal direction.

3.1.6. Special Factors Related to Mine Disaster Influence Coefficient. In order to create a simple and unified mathematical model for various tunnel disasters, we consider special factors related to mine disaster, which refers to the extreme cases of different tunnel disasters, denoted by $k_{d i}$. Its value is in $\{1,+\infty\}$, and 1 indicates that this tunnel is normal and there is not exist mine disaster's influence, and $+\infty$ means this tunnel cannot be passed. There are a lot of factors which can cause the tunnel cannot be passed, for example:

(1) there is serious landslide in the tunnel and people cannot go through it.

(2) There exists high temperature (or large amount of smoke, toxic gas) in the tunnel, people cannot bear it.

(3) There is flood in the tunnel and the water height is more than people's bear limitation.

3.2. The Normalization of Tunnel Weights. According to the above calculation model, the tunnel equivalent length's range is $(0,+\infty]$, in which $+\infty$ indicates that the tunnel cannot 
TABLE 2: Value of parameter $\alpha_{h}$.

\begin{tabular}{lccc}
\hline $\begin{array}{l}\text { Height of gas } \\
\text { layer }(\mathrm{m})\end{array}$ & Coefficient $\alpha_{h}$ & $\begin{array}{c}\text { Height of gas } \\
\text { layer }(\mathrm{m})\end{array}$ & Coefficient $\alpha_{h}$ \\
\hline$>6$ & 0 & $1.6-1.8$ & 2 \\
$4-6$ & 0.1 & $1.4-1.6$ & 5 \\
$2-4$ & 0.5 & $1-1.4$ & 10 \\
$1.8-2$ & 1 & $<1$ & 100 \\
\hline
\end{tabular}

TABLE 3: Value of parameter $L_{r}$.

\begin{tabular}{lc}
\hline Visibility distance $(\mathrm{m})$ & Coefficient $L_{r}$ \\
\hline$>20$ & 1 \\
$10-20$ & 1.25 \\
$5-10$ & 2.95 \\
$3-5$ & 6.25 \\
$<3$ & 12.5 \\
\hline
\end{tabular}

be got through. For the convenience of data processing, the data is mapped to range $(0,1]$. The linear mapping is used as follows:

$$
w_{i}=0.1+\frac{\left(l_{i}-\min (l)\right)}{(\max (l)-\min (l))} *(0.9-0.1) .
$$

In which $\min (l)$ refers to the minimum equivalent length of all tunnels', $\max (l)$ is the maximum equivalent length of all tunnels' (except for the length value $+\infty$ ). This function means the closer to 0 the values after mapping is, and the easier to pass through it. When the value is 1 , it means the tunnel cannot be passed.

Based on calculated weights and the tunnel topology graph $G(V, E)$, the following improved ant algorithm can do a good route planning processing.

\section{Searching the Optimal Escape Routes with Improved Ant Algorithm}

This paper presents an improved ant algorithm which can quickly and effectively find the best route and several sub optimal routes from $V_{o}$ (the trapped personnel position) to $V_{e}$ (the safety point) in the tunnel network. There are two improvements to the ant algorithm: firstly, tunnel zoning characteristics are used to influence the ants' behaviors and improve the searching efficiency of ants; secondly, the strategy of meeting of ants and the ant death rules are modified to improve the ant algorithm's performance.

4.1. Calculation Steps of the Improved Ant Algorithm. Basic steps of the improved ant algorithm are as follows.

Step 1. Based on the above tunnel weights calculation model, weighted graph $G$ is built. The trapped personnel position is denoted by $V_{o}$ and the exit point (safety point) is denoted by $V_{e}$ in graph $G$. The zoning attribute information is loaded.

Step 2. Initializes the ant algorithm's parameters including $\alpha$, $\beta$, iter, $C_{\max }$, the pheromone trail matrix and the ant routes record table, and so forth; assigns the zoning number to each node according to the zoning attribute information acquired; arranges the ants' position with the distribution requirements of Section 4.2.

Step 3. In the graph $G$, every ant is constructed an accessible node set in accordance with the moving rules in Section 4.2, and the tunnel zoning may influence the ants' accessible node set. The ant selects the next node by formula (14), and puts the selected node into its route record. After every live ant has selected a node, the system will judge whether the ant is dead or not (based on the rules described in Section 4.3). The procedure is repeated until all ants are dead and by this manner an iteration step is finished. The whole ant algorithm calculating procedure requires $C_{\max }$ times iteration.

Step 4. Updates the pheromone trail matrix and the parameter $\alpha, \beta$ in accordance with the update rules in Section 4.4. Records the optimal route and $L$ alternative routes in this iteration, and denotes it by $\mathrm{OP}_{i}^{j}$ ( $i$ is the number of current iteration; $j=0,1,2, \ldots, L ; j=0$ indicates the optimal route). According to the information of the current underground tunnels, weighted graph $G^{\prime}$ is reconstructed. The change rate of $\Delta G$ is calculated according to the formula (19). If $\Delta G$ is less than a small constant $\delta$, it changes optimal routes of all executed iterations if these routes contain changed tunnels. If $\Delta G$ is greater than $\delta$, a new ant algorithm is restarted (go to Step 1).

Step 5. Initializes ant routes recording table; fixes and controls pheromone trail matrix by the MMAS method; updates parameter iter as (iter +1$)$. If current iter's value is less than $C_{\text {max }}$, go to Step 2 .

Step 6. From the records of the iterations' routes $\mathrm{OP}_{i}^{j}(i=$ $\left.1,2, \ldots, C_{\max }, j=0,1,2, \ldots, L\right)$, select the optimal route and $L$ suboptimal routes for the current underground trapped workers.

4.2. Ants'Distribution and Moving Rules. The $V_{o}$ and $V_{e}$ nodes of the graph $G$ are set $m$ ants separately. For the ant $k$, its current node $i$ 's accessible nodes set is built as

$$
\operatorname{allow}_{i}^{k}=A_{i}-B_{k}-(1-p) C_{k}, \quad p=\{0,1\} .
$$

In (13), if the node $i$ is in the backbone zone $S_{0}$ or expected zone $S_{e}, p$ 's value is 1 , else $p$ 's value is 0 . The set $A_{i}$ is \{nodes | the node which connected with node $i\}$, and the set $B_{k}$ is \{nodes | the node that the ant $k$ has passed\}, and the set $C_{k}$ is \{nodes | the node which does not belong to zone $S_{0}$ and zone $S_{e}$ \}. Through the use of the set $C_{k}$, unnecessary detour can be avoided and the searching efficiency can be improved.

In accordance with the probability value calculated through (14), the ant $k$ selects the next node in allow ${ }_{i}^{k}$. Formula (14) is described as follows:

$$
p_{i j}^{k}= \begin{cases}\frac{\tau_{i j}^{\alpha} w_{i j}^{\beta}}{\sum_{s \in \text { allow }_{i}^{k} \tau_{i s}^{\alpha} w_{i s}^{\beta}}}, & j \in \text { allow }_{i}^{k}, \\ 0, & \text { else. }\end{cases}
$$


In (14), $\alpha, \beta$ are factors of importance of the pheromone trail and the heuristic function respectively. And $\tau_{i j}, w_{i j}$ are pheromone trail concentration and weights respectively from the node $i$ to the node $j$. The heuristic function is defined as weights between the current nodes.

4.3. The Rules of Meeting and Death of Ants. Every ant has attributes of a start node and an expected node. There are two improvements in meeting and death strategy showed in rule (2) and (4).

These rules are as follows.

(1) If there is no way for the ant, the ant dies and is marked with no available route status.

(2) When two ants meet, if the expecting point of one ant and the start point of the other ant intersect, the ant having short route gives its route to another, and then the latter dies and is marked with an available route status. The former moves on.

(3) If the ant reaches the expected point, the ant dies and is marked with an available route status.

(4) Sets a physical power parameter to the trapped workers group $i$ and denotes it as $\mathrm{PF}_{i}$ which will reduce gradually. The $\mathrm{PF}_{i}$ parameters are assigned to ants. The ant will die when $\mathrm{PF}_{i}$ of the ant is reduced to zero no matter what status the ant is in and then it is marked with no available route status.

4.4. Update of Pheromone Trail and Main Parameters. When one iteration processing is completed, the pheromone matrix and the parameter $\alpha$ and $\beta$ need to be updated. To prevent premature problem, the MMAS method [10] is used in the pheromone updating procedure. After an iteration processing, only the pheromone of this iteration optimal route is updated, according to (15) and (16). In addition, in order to improve the convergence of the later iteration and the early intelligence, factors $\alpha$ and $\beta$ are dynamically changed at a fixed length between two iterations. At the later stage, $\alpha$ acts as the major factor; at the early stage, $\beta$ acts as the major factor. See (17) and (18):

$$
\begin{gathered}
\tau_{i j}(t+1)=(1-\rho) \tau_{i j}(t)+\Delta \tau_{i j}(t), \\
\Delta \tau_{i j}= \begin{cases}\frac{Q}{\sum w}, & \operatorname{arc}(i, j) \text { in optimal route, } \\
0, & \operatorname{arc}(i, j) \text { not in optimal route, }\end{cases} \\
\alpha(t+1)=\alpha(t)+\Delta \alpha, \quad \Delta \alpha=\frac{\left(\alpha_{\max }-\alpha_{\min }\right)}{c_{\max }}, \\
\beta(t+1)=\beta(t)-\Delta \beta, \quad \Delta \beta=\frac{\left(\beta_{\max }-\beta_{\min }\right)}{c_{\max }} .
\end{gathered}
$$

Formula (15) gives the pheromone relationship between the iteration $(t+1)$ and the iteration $t$, and $\rho$ is the volatile factor of the pheromone, and $\Delta \tau_{i j}$ is the incremental pheromone.

Formula (16) is built based on MMAS strategy, only if the $\operatorname{arc}(i, j)$ is in the optimal route of the iteration, the pheromone
TABLE 4: Parameters value of the ant algorithm.

\begin{tabular}{lc}
\hline Parameters & Value \\
\hline$\alpha$ & $1-2$ \\
$\beta$ & $2-1$ \\
$\rho$ & 0.3 \\
$Q$ (in formula (16)) & 1 \\
$C_{\max }$ & 150 \\
$m$ (the number of ants) & 16 \\
$L$ (the number of alternative routes) & 2 \\
\hline
\end{tabular}

of the $\operatorname{arc}(i, j)$ is updated. $\sum w$ is the length of the current optimal route.

In (17), $\alpha_{\max }$ is the maximum of $\alpha$, and $\alpha_{\min }$ is the minimum of $\alpha, c_{\max }$ is the total iteration number. The meaning of formula (18) is similar to the meaning of formula (17).

4.5. Condition of the Algorithm Stopping. When one iteration calculation is completed, according to current information, underground tunnel diagram $G^{\prime}$ is reconstructed, and the diagram's change rate can be represented as

$$
\Delta G(t)=\frac{\left|G^{\prime}(t)-G\right|}{G} .
$$

In (19), $\left|G^{\prime}(t)-G\right|$ indicates the changing number of arcs between $G^{\prime}$ of iteration $t$ and the original $G$, and $G$ indicates the total number of arcs of the original diagram.

When $\Delta G$ is less than the small value $\delta$, weights of the related arcs in the optimal routes of executed iterations are updated. Under this situation, the optimal length of executed iterations changes, but the order of passed node does not change. When $\Delta G$ is more than $\delta$, current calculation is stopped and a new algorithm calculation is restarted.

\section{Implementation of the Algorithm and the Experimental Results}

5.1. Parameter Setting. Different $\alpha, \beta, \rho$ parameter values have different influence to the stability and convergence of the ant algorithm. Based on literature [14] and relative experiments, to an underground tunnel network which has 210 tunnels and 147 nodes, these parameters' values are set in Table 4 .

5.2. Experiment Data. The underground tunnel data come from a large sized coal mine in China. Partial data are showed in Table 5.

In Table 5, some simulated factors (such as slope, tunnel particle concentrations influence, tunnel crowded degree and special factors influence) are created based on original data. The network topology of the mine and its zoning result is shown in Figure 2.

The Matlab tool is used to realize the data processing and the ant algorithm. The node 83 is set as $V_{o}$ and the node 1 is set as $V_{e}$. The iteration curve of the ant algorithm is shown in Figure 3. 
TABLE 5: Partial data and weights of underground tunnel network.

\begin{tabular}{|c|c|c|c|c|c|c|c|c|c|}
\hline Start point & $\begin{array}{l}\text { End } \\
\text { point }\end{array}$ & $\begin{array}{c}\text { Tunnel } \\
\text { type } \\
\text { influenc } k_{t i}\end{array}$ & $\begin{array}{l}\text { Wind } \\
\text { speed } \\
(\mathrm{m} / \mathrm{s})\end{array}$ & $\begin{array}{l}\text { Angle of } \\
\text { slope }\left(^{\circ}\right)\end{array}$ & $\begin{array}{c}\text { Special } \\
\text { factors } \\
\text { influence } \\
k_{d i}\end{array}$ & $\begin{array}{l}\text { The lowest } \\
\text { height of } \\
\text { smoke layer } \\
\text { (m) }\end{array}$ & $\begin{array}{l}\text { Visibility } \\
\text { distance } \\
\text { (m) }\end{array}$ & $\begin{array}{c}\text { Body } \\
\text { interval } \\
(\mathrm{m})\end{array}$ & $\begin{array}{l}\text { Length } \\
\text { (m) }\end{array}$ \\
\hline 31 & 30 & $\infty$ & 0 & 0 & 1 & 6 & 20 & 1 & 40 \\
\hline 30 & 32 & 1 & 10.3 & 10 & 1 & 6 & 20 & 0.8 & 35 \\
\hline 32 & 33 & 1 & 5.6 & 0 & 1 & 6 & 20 & 0.8 & 242 \\
\hline 35 & 12 & 0.5 & 9.4 & 0 & 1 & 5 & 20 & 0.8 & 80 \\
\hline 12 & 37 & 1 & 10.3 & 10 & $\infty$ & 5 & 20 & 0.8 & 281 \\
\hline$\ldots$ & $\ldots$ & $\ldots$ & $\ldots$ & $\ldots$ & $\ldots$ & $\ldots$ & $\ldots$ & $\ldots$ & $\ldots$ \\
\hline
\end{tabular}

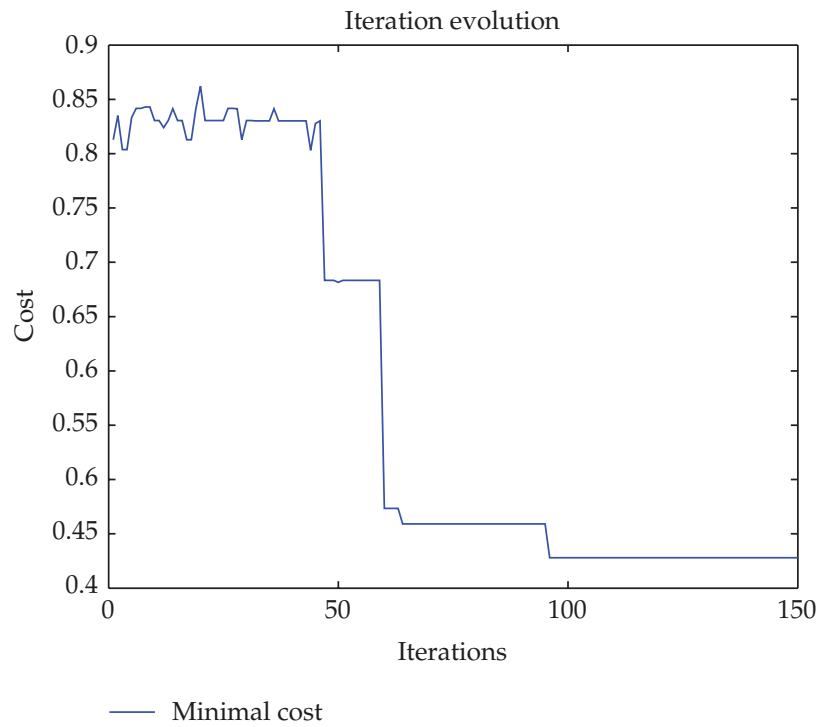

FIGURE 3: Iteration curve of the ant algorithm.

In Figure 3, the $x$-axis represents the number of iterations, and the ordinate represents the minimum cost of the current iteration. The cost is the sum of arc weights in the optimal route of the current iteration. From the chart we can see the algorithm has better convergence ability: after three convergences the global optimal route is found in 100 iterations about.

The algorithm procedure loads related parameters and experimental data firstly and then does calculation. Five calculation results are shown in Table 6. The experimental data is showed in Table 7.

In Table 6, what in small brackets is the sequence of passed nodes. To observe the calculated routes intuitively, the first running result is marked in Figure 2. The red line indicates the optimal route, and the green line is the first alternative route and the blue line is the second alternative route.

In fact, through the manual calculation we know the shortest cost between node 83 and node 1 is 0.42799 and the route is $(83,84,82,80,77,76,74,63,57,55,45,1)$. From results in Table 6 we can see the best route is found steadily, meanwhile, two alternative routes are found but not stable.

\section{Conclusion}

An improved ant algorithm is proposed in this paper to solve the escape routes planning problem of underground coal mines. A simple unified tunnel weights calculation model is designed, which considers various impact factors. By the tunnel zoning method, searching efficiency of the ant algorithm has been improved effectively. The MMAS method is used to optimize the meeting strategy to improve the performance of the ant algorithm. In the algorithm's processing procedure, when small part of mine networks changes, the system may fix the optimal routes and avoid starting a new processing procedure. The algorithm was achieved in the Matlab platform and the best route was worked out steadily. The algorithm obtained good results when treating the data of a large coal mine of China. The proposed algorithm can be used in underground mine disaster rescue. 


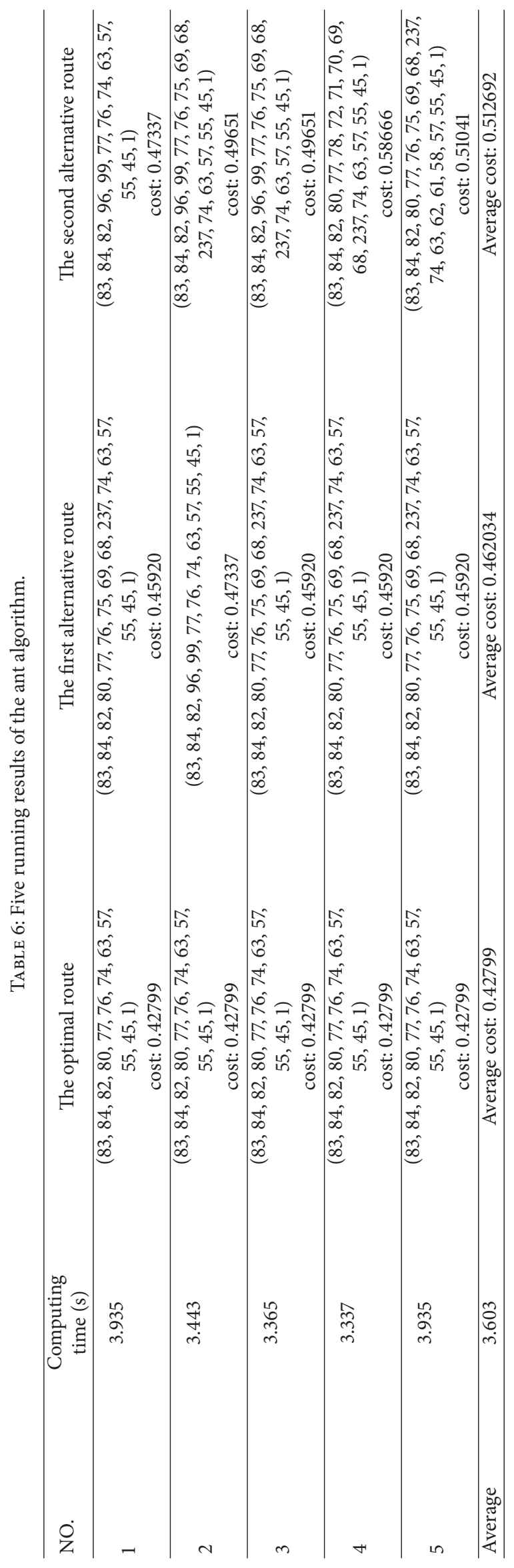


TABLE 7: Experimental data.

\begin{tabular}{|c|c|c|c|c|c|c|c|c|c|}
\hline Start point & $\begin{array}{l}\text { End } \\
\text { point }\end{array}$ & $\begin{array}{l}\text { Tunnel type } \\
\text { influence } k_{t i}\end{array}$ & $\begin{array}{l}\text { Wind } \\
\text { speed } \\
(\mathrm{m} / \mathrm{s})\end{array}$ & $\begin{array}{l}\text { Angle of } \\
\text { slope }\left({ }^{\circ}\right)\end{array}$ & $\begin{array}{c}\text { Special } \\
\text { factors } \\
\text { influence } k_{d i}\end{array}$ & $\begin{array}{l}\text { The lowest } \\
\text { height of } \\
\text { smoke } \\
\text { layer }(\mathrm{m})\end{array}$ & $\begin{array}{l}\text { Visibility } \\
\text { distance } \\
(\mathrm{m})\end{array}$ & $\begin{array}{l}\text { Body } \\
\text { interval } \\
(\mathrm{m})\end{array}$ & $\begin{array}{l}\text { Length } \\
(\mathrm{m})\end{array}$ \\
\hline 31 & 30 & $\infty$ & 0 & 0 & 1 & 6 & 20 & 1 & 40 \\
\hline 30 & 32 & 1 & 10.3 & 10 & 1 & 6 & 20 & 0.8 & 35 \\
\hline 32 & 33 & 1 & 5.6 & 0 & 1 & 6 & 20 & 0.8 & 242 \\
\hline 35 & 12 & 0.5 & 9.4 & 0 & 1 & 5 & 20 & 0.8 & 80 \\
\hline 12 & 37 & 1 & 10.3 & 10 & $\infty$ & 5 & 20 & 0.8 & 281 \\
\hline 37 & 38 & 1 & 10.4 & 0 & 1 & 5 & 20 & 0.8 & 135 \\
\hline 38 & 40 & 1 & 10.4 & 0 & 1 & 5 & 20 & 0.8 & 43 \\
\hline 40 & 42 & 0.5 & 10.2 & 0 & 1 & 5 & 20 & 0.8 & 28 \\
\hline 45 & 46 & 1 & 0 & 0 & 1 & 5 & 20 & 0.8 & 136.4 \\
\hline 46 & 40 & 1 & 0.3 & -20 & 1 & 5 & 20 & 1 & 70.6 \\
\hline 46 & 38 & 1 & 0.3 & -20 & 1 & 6 & 20 & 1 & 27.6 \\
\hline 42 & 129 & 1 & 6.4 & 0 & 1 & 6 & 20 & 1 & 194 \\
\hline 50 & 51 & 0.5 & 10.9 & 0 & 1 & 6 & 20 & 1 & 40 \\
\hline 52 & 51 & 1 & 0 & 0 & $\infty$ & 6 & 20 & 1 & 56 \\
\hline 51 & 53 & 1 & 10.9 & 0 & 1 & 6 & 20 & 1 & 120 \\
\hline 50 & 52 & 1 & 0 & 0 & 1 & 6 & 20 & 1 & 40 \\
\hline 1 & 45 & 0.5 & 3.3 & 10 & 1 & 6 & 20 & 1 & 670 \\
\hline 45 & 55 & 0.5 & 2.5 & 0 & 1 & 6 & 20 & 1 & 67 \\
\hline 56 & 37 & 0.5 & 0.6 & 0 & 1 & 3 & 20 & 1 & 40 \\
\hline 56 & 55 & 0.5 & 4.9 & 0 & 1 & 3 & 20 & 1 & 131.5 \\
\hline 55 & 57 & 0.5 & 0.1 & 0 & 1 & 3 & 20 & 1 & 50 \\
\hline 57 & 58 & 0.5 & 10.9 & 0 & 1 & 3 & 20 & 1 & 100 \\
\hline 59 & 58 & 0.5 & 0.6 & 0 & 1 & 3 & 20 & 1 & 100 \\
\hline 58 & 60 & 0.5 & 4.9 & 15 & 1 & 3 & 20 & 1 & 580 \\
\hline 61 & 59 & 0.5 & 0 & 0 & 1 & 3 & 20 & 1 & 45 \\
\hline 36 & 61 & 0.5 & 10.5 & 0 & 1 & 3 & 20 & 1 & 517 \\
\hline 61 & 62 & 1 & 10.6 & 0 & 1 & 6 & 20 & 1 & 28 \\
\hline 62 & 63 & 1 & 0.2 & 0 & 1 & 6 & 20 & 1 & 40 \\
\hline 63 & 57 & 1 & 10.4 & 0 & 1 & 6 & 20 & 1 & 85 \\
\hline 65 & 59 & 1 & 0.6 & 0 & 1 & 6 & 20 & 1 & 26 \\
\hline 126 & 65 & 1 & 0 & 0 & 1 & 6 & 20 & 1 & 20 \\
\hline 66 & 65 & 1 & 0.4 & -15 & 1 & 6 & 20 & 1 & 40 \\
\hline 67 & 66 & 1 & 0.5 & 0 & 1 & 6 & 20 & 1 & 72 \\
\hline 62 & 67 & 1 & 10 & 0 & 1 & 6 & 20 & 1 & 27 \\
\hline 67 & 237 & 1 & 10.8 & 0 & 1 & 6 & 20 & 1 & 348 \\
\hline 69 & 68 & 0.5 & 1.9 & 0 & 1 & 6 & 20 & 1 & 20 \\
\hline 71 & 70 & 0.5 & 0 & 0 & 1 & 6 & 15 & 1 & 15 \\
\hline 72 & 70 & 0.5 & 1.6 & 0 & $\infty$ & 6 & 20 & 0.7 & 30 \\
\hline 74 & 63 & 0.5 & 11 & 0 & 1 & 3 & 20 & 0.7 & 375 \\
\hline 69 & 75 & 0.5 & 0 & 0 & 1 & 3 & 20 & 0.7 & 20 \\
\hline 76 & 74 & 0.5 & 10.4 & 20 & 1 & 3 & 20 & 0.7 & 50 \\
\hline 75 & 76 & 0.5 & 10.4 & 0 & 1 & 3 & 20 & 0.7 & 22 \\
\hline 77 & 76 & 0.5 & 0 & 20 & 1 & 3 & 20 & 0.7 & 40 \\
\hline 78 & 77 & 0.5 & 2.8 & 0 & 1 & 3 & 20 & 0.7 & 25 \\
\hline
\end{tabular}


TABle 7: Continued.

\begin{tabular}{|c|c|c|c|c|c|c|c|c|c|}
\hline Start point & $\begin{array}{l}\text { End } \\
\text { point }\end{array}$ & $\begin{array}{l}\text { Tunnel type } \\
\text { influence } k_{t i}\end{array}$ & $\begin{array}{l}\text { Wind } \\
\text { speed } \\
(\mathrm{m} / \mathrm{s})\end{array}$ & $\begin{array}{l}\text { Angle of } \\
\text { slope }\left(^{\circ}\right)\end{array}$ & $\begin{array}{c}\text { Special } \\
\text { factors } \\
\text { influence } k_{d i}\end{array}$ & $\begin{array}{l}\text { The lowest } \\
\text { height of } \\
\text { smoke } \\
\text { layer }(\mathrm{m})\end{array}$ & $\begin{array}{c}\text { Visibility } \\
\text { distance } \\
\text { (m) }\end{array}$ & $\begin{array}{c}\text { Body } \\
\text { interval } \\
(\mathrm{m})\end{array}$ & $\begin{array}{l}\text { Length } \\
(\mathrm{m})\end{array}$ \\
\hline 129 & 78 & 1 & 6.4 & 0 & 1 & 3 & 20 & 0.7 & 223 \\
\hline 52 & 79 & 1 & 0 & 0 & 1 & 3 & 20 & 0.7 & 460 \\
\hline 125 & 92 & 1 & 0 & 0 & 1 & 3 & 20 & 0.7 & 35 \\
\hline 80 & 93 & 1 & 0 & 20 & 1 & 6 & 20 & 0.7 & 90 \\
\hline 82 & 84 & 0.5 & 2.7 & 0 & 1 & 6 & 20 & 0.7 & 40 \\
\hline 83 & 81 & 0.5 & 2.6 & 0 & 1 & 6 & 20 & 1.5 & 240 \\
\hline 84 & 83 & 0.5 & 2.7 & 0 & 1 & 6 & 20 & 1.5 & 630 \\
\hline 128 & 56 & 0.5 & 5.6 & 0 & 1 & 6 & 20 & 1.5 & 300 \\
\hline 87 & 86 & 0.5 & 4.3 & 0 & 1 & 5 & 20 & 1.5 & 25 \\
\hline 88 & 87 & 0.5 & 3 & 0 & 1 & 5 & 20 & 1.5 & 20 \\
\hline 33 & 88 & 0.5 & 2.1 & 0 & 1 & 5 & 20 & 1.5 & 47 \\
\hline 33 & 89 & 1 & 3.4 & 0 & 1 & 5 & 20 & 1.5 & 27 \\
\hline 89 & 90 & 1 & 2.5 & 0 & 1 & 5 & 20 & 1.5 & 20 \\
\hline 90 & 86 & 1 & 1.6 & 0 & 1 & 5 & 20 & 1.5 & 45 \\
\hline 90 & 87 & 1 & 0 & 0 & 1 & 5 & 20 & 1.5 & 20 \\
\hline 89 & 88 & 1 & 1.3 & 0 & 1 & 5 & 20 & 1.5 & 20 \\
\hline 31 & 91 & 1 & 4 & -20 & 1 & 5 & 20 & 1.5 & 286 \\
\hline 81 & 93 & 1 & 2.6 & 0 & 1 & 6 & 20 & 1.5 & 640 \\
\hline 93 & 94 & 1 & 2.7 & 0 & 1 & 6 & 20 & 1.5 & 35 \\
\hline 53 & 80 & 1 & 10.9 & 0 & 1 & 6 & 20 & 1.5 & 90 \\
\hline 80 & 82 & 1 & 10.9 & 0 & 1 & 6 & 20 & 1.5 & 204 \\
\hline 77 & 99 & 1 & 4.7 & 0 & 1 & 6 & 20 & 1.5 & 254 \\
\hline 80 & 77 & 1 & 2 & 0 & 1 & 6 & 20 & 1.5 & 40 \\
\hline 82 & 96 & 0.5 & 9.1 & 0 & 1 & 6 & 20 & 1.5 & 61 \\
\hline 96 & 97 & 1 & 8.5 & 15 & 1 & 6 & 20 & 1.5 & 40 \\
\hline 97 & 98 & 1 & 0 & 0 & 1 & 6 & 20 & 1.5 & 196 \\
\hline 99 & 98 & 1 & 3.5 & 0 & 1 & 6 & 20 & 1.2 & 80 \\
\hline 96 & 99 & 1 & 0.6 & 15 & 1 & 3 & 20 & 1.2 & 40 \\
\hline 99 & 110 & 1 & 1.9 & 0 & $\infty$ & 3 & 20 & 1.2 & 29.2 \\
\hline 98 & 101 & 1 & 3.4 & 15 & 1 & 3 & 20 & 1.2 & 40 \\
\hline 101 & 102 & 1 & 0.1 & 0 & 1 & 3 & 20 & 1.2 & 265.2 \\
\hline 103 & 241 & 0.5 & 3.1 & 0 & 1 & 3 & 20 & 1.2 & 163.3 \\
\hline 104 & 103 & 1 & 5.3 & -20 & 1 & 3 & 20 & 1.2 & 21.2 \\
\hline 105 & 104 & 0.5 & 3.7 & 0 & 1 & 3 & 20 & 1.2 & 110 \\
\hline 106 & 105 & 0.5 & 10.8 & 0 & 1 & 3 & 20 & 1.2 & 40 \\
\hline 106 & 107 & 1 & 0.1 & 0 & 1 & 3 & 20 & 1.2 & 75 \\
\hline 98 & 107 & 1 & 0.1 & -15 & 1 & 3 & 20 & 1.2 & 50 \\
\hline 102 & 107 & 1 & 10.1 & 0 & 1 & 6 & 20 & 1.2 & 85 \\
\hline 107 & 108 & 1 & 10.1 & 0 & 1 & 6 & 20 & 1.2 & 218.2 \\
\hline 109 & 108 & 0.5 & 8.1 & 0 & 1 & 6 & 20 & 1.2 & 50 \\
\hline 110 & 106 & 0.5 & 10.8 & 0 & 1 & 6 & 20 & 1.2 & 70 \\
\hline 68 & 110 & 1 & 10.2 & 0 & 1 & 6 & 20 & 1.2 & 243 \\
\hline 110 & 100 & 1 & 1.1 & 10 & 1 & 6 & 5 & 1.2 & 5 \\
\hline 71 & 112 & 0.5 & 1.7 & 0 & 1 & 6 & 20 & 1.2 & 128 \\
\hline
\end{tabular}


TABLE 7: Continued.

\begin{tabular}{|c|c|c|c|c|c|c|c|c|c|}
\hline Start point & $\begin{array}{l}\text { End } \\
\text { point }\end{array}$ & $\begin{array}{l}\text { Tunnel type } \\
\text { influence } k_{t i}\end{array}$ & $\begin{array}{l}\text { Wind } \\
\text { speed } \\
(\mathrm{m} / \mathrm{s})\end{array}$ & $\begin{array}{l}\text { Angle of } \\
\text { slope }\left(^{\circ}\right)\end{array}$ & $\begin{array}{c}\text { Special } \\
\text { factors } \\
\text { influence } k_{d i}\end{array}$ & $\begin{array}{l}\text { The lowest } \\
\text { height of } \\
\text { smoke } \\
\text { layer }(\mathrm{m})\end{array}$ & $\begin{array}{l}\text { Visibility } \\
\text { distance } \\
(\mathrm{m})\end{array}$ & $\begin{array}{c}\text { Body } \\
\text { interval } \\
(\mathrm{m})\end{array}$ & $\begin{array}{l}\text { Length } \\
(\mathrm{m})\end{array}$ \\
\hline 72 & 71 & 0.5 & 2.4 & 0 & 1 & 6 & 14 & 1.2 & 14 \\
\hline 112 & 68 & 0.5 & 0.8 & 0 & 1 & 6 & 11 & 1.2 & 11 \\
\hline 237 & 113 & 1 & 4.3 & 0 & 1 & 5 & 20 & 0.8 & 65.1 \\
\hline 113 & 141 & 1 & 2 & 10 & 1 & 5 & 20 & 0.8 & 248 \\
\hline 1 & 131 & 1 & 0.1 & -15 & 1 & 5 & 20 & 0.8 & 50 \\
\hline 60 & 115 & 1 & 10.3 & 0 & 1 & 5 & 20 & 0.8 & 50 \\
\hline 105 & 241 & 1 & 8.1 & 0 & 1 & 5 & 20 & 0.8 & 130 \\
\hline 35 & 91 & 1 & 9.5 & 10 & 1 & 5 & 20 & 0.8 & 40 \\
\hline 91 & 138 & 0.5 & 10.4 & 0 & 1 & 5 & 20 & 0.8 & 40 \\
\hline 108 & 75 & 0.5 & 10.7 & 20 & 1 & 5 & 20 & 0.8 & 95 \\
\hline 78 & 72 & 0.5 & 3 & 0 & 1 & 5 & 7.6 & 0.8 & 7.6 \\
\hline 81 & 94 & 1 & 0 & 0 & 1 & 5 & 20 & 0.8 & 690 \\
\hline 94 & 125 & 1 & 2.7 & 0 & 1 & 5 & 20 & 0.8 & 61.2 \\
\hline 53 & 125 & 1 & 0 & 0 & 1 & 5 & 20 & 0.8 & 57 \\
\hline 125 & 74 & 1 & 2.7 & -20 & 1 & 5 & 20 & 0.8 & 530 \\
\hline 127 & 126 & 0.5 & 0 & 0 & 1 & 5 & 20 & 0.8 & 40 \\
\hline 66 & 127 & 0.5 & 0 & 20 & 1 & 5 & 15 & 0.8 & 15 \\
\hline 86 & 128 & 0.5 & 5.9 & 0 & 1 & 6 & 20 & 0.8 & 24.7 \\
\hline 50 & 129 & 1 & 0 & 0 & 1 & 6 & 20 & 0.8 & 40 \\
\hline 70 & 69 & 1 & 1.8 & 20 & 1 & 6 & 20 & 0.8 & 65 \\
\hline 131 & 60 & 1 & 0 & 0 & 1 & 6 & 20 & 0.8 & 20 \\
\hline 1 & 115 & 0.5 & 10.4 & -15 & 1 & 6 & 20 & 0.8 & 25 \\
\hline 32 & 34 & 0.5 & 10 & 0 & 1 & 6 & 20 & 0.8 & 100 \\
\hline 136 & 34 & 0.5 & 0 & 0 & 1 & 6 & 20 & 0.8 & 46.1 \\
\hline 136 & 137 & 1 & 10.1 & 0 & 1 & 6 & 20 & 0.8 & 210 \\
\hline 137 & 35 & 1 & 11 & 0 & 1 & 6 & 20 & 0.8 & 41.4 \\
\hline 138 & 36 & 1 & 10.4 & 0 & 1 & 6 & 20 & 0.8 & 39 \\
\hline 112 & 139 & 1 & 0 & 0 & 1 & 6 & 20 & 0.8 & 26 \\
\hline 100 & 109 & 1 & 4.3 & 0 & 1 & 6 & 20 & 0.8 & 40 \\
\hline 142 & 145 & 0.5 & 0 & 0 & 1 & 6 & 20 & 0.8 & 52.2 \\
\hline 144 & 145 & 0.5 & 0 & 0 & 1 & 6 & 20 & 0.8 & 71 \\
\hline 143 & 144 & 0.5 & 0 & 0 & 1 & 6 & 20 & 0.8 & 71 \\
\hline 141 & 143 & 0.5 & 0.4 & 0 & $\infty$ & 6 & 20 & 0.8 & 71 \\
\hline 148 & 140 & 1 & 1.4 & 0 & 1 & 6 & 20 & 0.8 & 52.2 \\
\hline 147 & 148 & 1 & 0 & -10 & 1 & 6 & 20 & 0.6 & 71 \\
\hline 146 & 147 & 1 & 0 & -10 & 1 & 5 & 20 & 0.6 & 71 \\
\hline 139 & 146 & 1 & 0.4 & 0 & 1 & 5 & 20 & 0.6 & 71 \\
\hline 143 & 146 & 1 & 0 & 0 & 1 & 5 & 20 & 0.6 & 25 \\
\hline 144 & 147 & 1 & 0 & 0 & 1 & 5 & 20 & 0.6 & 25 \\
\hline 145 & 148 & 1 & 0 & 0 & 1 & 5 & 20 & 0.6 & 25 \\
\hline 149 & 150 & 0.5 & 4.4 & 0 & 1 & 5 & 20 & 0.6 & 265.2 \\
\hline 141 & 151 & 0.5 & 2.2 & 20 & 1 & 5 & 20 & 0.6 & 150 \\
\hline 152 & 153 & 0.5 & 2.3 & 20 & 1 & 5 & 20 & 0.6 & 165 \\
\hline 153 & 154 & 0.5 & 2.3 & 0 & 1 & 5 & 20 & 0.6 & 160 \\
\hline
\end{tabular}


TABle 7: Continued.

\begin{tabular}{|c|c|c|c|c|c|c|c|c|c|}
\hline Start point & $\begin{array}{l}\text { End } \\
\text { point }\end{array}$ & $\begin{array}{l}\text { Tunnel type } \\
\text { influence } k_{t i}\end{array}$ & $\begin{array}{l}\text { Wind } \\
\text { speed } \\
(\mathrm{m} / \mathrm{s})\end{array}$ & $\begin{array}{l}\text { Angle of } \\
\text { slope }\left(^{\circ}\right)\end{array}$ & $\begin{array}{c}\text { Special } \\
\text { factors } \\
\text { influence } k_{d i}\end{array}$ & $\begin{array}{l}\text { The lowest } \\
\text { height of } \\
\text { smoke } \\
\text { layer }(\mathrm{m})\end{array}$ & $\begin{array}{l}\text { Visibility } \\
\text { distance } \\
\text { (m) }\end{array}$ & $\begin{array}{l}\text { Body } \\
\text { interval } \\
(\mathrm{m})\end{array}$ & $\begin{array}{l}\text { Length } \\
(\mathrm{m})\end{array}$ \\
\hline 154 & 149 & 1 & 4.3 & 0 & 1 & 5 & 20 & 0.6 & 20 \\
\hline 113 & 155 & 1 & 2.1 & 0 & 1 & 6 & 10 & 0.6 & 10 \\
\hline 155 & 156 & 1 & 2.1 & 0 & 1 & 6 & 20 & 0.6 & 159.6 \\
\hline 156 & 157 & 1 & 2.1 & 10 & 1 & 6 & 20 & 0.6 & 165.8 \\
\hline 157 & 158 & 1 & 2 & 0 & 1 & 6 & 20 & 0.6 & 155.1 \\
\hline 158 & 154 & 1 & 1.8 & 0 & 1 & 6 & 20 & 0.6 & 25.5 \\
\hline 157 & 153 & 1 & 0 & 0 & 1 & 6 & 20 & 0.6 & 26.9 \\
\hline 156 & 152 & 1 & 0 & 0 & 1 & 6 & 20 & 0.6 & 26.6 \\
\hline 155 & 151 & 1 & 0 & 0 & 1 & 6 & 20 & 0.6 & 27.9 \\
\hline 140 & 109 & 1 & 3.7 & 0 & 1 & 6 & 20 & 1 & 25.7 \\
\hline 142 & 140 & 1 & 2.6 & 0 & 1 & 6 & 20 & 1 & 25.2 \\
\hline 97 & 159 & 1 & 8.6 & -10 & 1 & 6 & 20 & 1 & 240 \\
\hline 159 & 160 & 1 & 4.1 & -10 & 1 & 6 & 20 & 1 & 44 \\
\hline 159 & 162 & 1 & 4.7 & 0 & 1 & 6 & 20 & 1 & 47 \\
\hline 162 & 163 & 1 & 2.6 & 0 & 1 & 6 & 14.4 & 1 & 14.4 \\
\hline 163 & 164 & 1 & 0 & 0 & 1 & 3 & 19 & 1 & 19 \\
\hline 162 & 164 & 1 & 1.7 & 0 & 1 & 3 & 20 & 1 & 33.4 \\
\hline 163 & 165 & 1 & 2.2 & 0 & 1 & 3 & 20 & 1 & 61.8 \\
\hline 164 & 165 & 1 & 2.4 & 0 & $\infty$ & 3 & 20 & 1 & 51.2 \\
\hline 165 & 104 & 1 & 4.6 & 20 & 1 & 3 & 20 & 1 & 92.3 \\
\hline 104 & 166 & 1 & 3 & 20 & 1 & 3 & 20 & 1 & 120 \\
\hline 166 & 167 & 1 & 2.7 & 0 & 1 & 3 & 20 & 1 & 157.9 \\
\hline 167 & 168 & 1 & 2.2 & 0 & 1 & 3 & 20 & 1 & 225.9 \\
\hline 168 & 169 & 1 & 2.2 & 0 & 1 & 3 & 20 & 1 & 201.4 \\
\hline 169 & 170 & 0.5 & 2.2 & 0 & 1 & 3 & 20 & 1 & 212.5 \\
\hline 170 & 171 & 0.5 & 2.2 & 0 & 1 & 3 & 20 & 1 & 202.8 \\
\hline 171 & 172 & 0.5 & 2.2 & 10 & 1 & 3 & 20 & 1 & 175.5 \\
\hline 172 & 173 & 0.5 & 2.2 & 10 & 1 & 3 & 20 & 1 & 197.5 \\
\hline 173 & 174 & 0.5 & 2.2 & 0 & 1 & 3 & 20 & 1 & 216.8 \\
\hline 174 & 175 & 1 & 2.2 & 0 & 1 & 3 & 20 & 1 & 203.9 \\
\hline 175 & 176 & 1 & 2.4 & 0 & 1 & 3 & 20 & 1 & 51.9 \\
\hline 176 & 177 & 1 & 0 & 0 & $\infty$ & 3 & 20 & 1 & 24.2 \\
\hline 177 & 178 & 1 & 0 & 0 & 1 & 6 & 20 & 1 & 23.5 \\
\hline 179 & 178 & 1 & 2.4 & 0 & 1 & 6 & 20 & 1 & 24.3 \\
\hline 179 & 176 & 1 & 0 & 0 & 1 & 6 & 20 & 1 & 23.5 \\
\hline 176 & 180 & 1 & 1.4 & 20 & 1 & 6 & 20 & 1 & 266.2 \\
\hline 180 & 181 & 1 & 1.4 & 0 & 1 & 6 & 20 & 1 & 1285.6 \\
\hline 182 & 100 & 1 & 3 & 0 & 1 & 6 & 20 & 1 & 9.2 \\
\hline 183 & 182 & 1 & 1.9 & 0 & 1 & 6 & 20 & 1 & 24.9 \\
\hline 184 & 183 & 1 & 2.6 & 0 & 1 & 6 & 20 & 1 & 151.2 \\
\hline 185 & 184 & 1 & 1.3 & 0 & 1 & 6 & 20 & 1 & 203.5 \\
\hline 181 & 185 & 1 & 1.4 & 0 & 1 & 6 & 20 & 1 & 207.6 \\
\hline 186 & 142 & 1 & 3.1 & 0 & 1 & 6 & 20 & 1 & 132.7 \\
\hline 187 & 186 & 1 & 4.4 & 0 & $\infty$ & 6 & 20 & 1 & 203.6 \\
\hline
\end{tabular}


TABle 7: Continued.

\begin{tabular}{|c|c|c|c|c|c|c|c|c|c|}
\hline Start point & $\begin{array}{l}\text { End } \\
\text { point }\end{array}$ & $\begin{array}{l}\text { Tunnel type } \\
\text { influence } k_{t i}\end{array}$ & $\begin{array}{l}\text { Wind } \\
\text { speed } \\
(\mathrm{m} / \mathrm{s})\end{array}$ & $\begin{array}{l}\text { Angle of } \\
\text { slope }\left(^{\circ}\right)\end{array}$ & $\begin{array}{c}\text { Special } \\
\text { factors } \\
\text { influence } k_{d i}\end{array}$ & $\begin{array}{l}\text { The lowest } \\
\text { height of } \\
\text { smoke } \\
\text { layer }(\mathrm{m})\end{array}$ & $\begin{array}{l}\text { Visibility } \\
\text { distance } \\
(\mathrm{m})\end{array}$ & $\begin{array}{c}\text { Body } \\
\text { interval } \\
(\mathrm{m})\end{array}$ & $\begin{array}{l}\text { Length } \\
(\mathrm{m})\end{array}$ \\
\hline 188 & 187 & 1 & 4.4 & 0 & 1 & 6 & 20 & 1 & 209 \\
\hline 150 & 188 & 1 & 4.4 & 0 & 1 & 6 & 20 & 1 & 112.9 \\
\hline 181 & 188 & 1 & 0 & -15 & 1 & 6 & 20 & 1 & 29.2 \\
\hline 187 & 185 & 1 & 0 & 0 & 1 & 6 & 20 & 1 & 30.3 \\
\hline 186 & 184 & 1 & 1.8 & 0 & 1 & 6 & 20 & 1 & 30.3 \\
\hline 101 & 160 & 1 & 1.2 & 0 & 1 & 6 & 20 & 1 & 240 \\
\hline 103 & 190 & 1 & 2.1 & 10 & 1 & 6 & 20 & 1 & 25 \\
\hline 167 & 190 & 1 & 0 & 10 & 1 & 6 & 20 & 1 & 29.3 \\
\hline 190 & 191 & 0.5 & 2.7 & 0 & 1 & 5 & 20 & 1 & 215.6 \\
\hline 191 & 168 & 0.5 & 0 & 0 & 1 & 5 & 20 & 1 & 35.8 \\
\hline 191 & 192 & 0.5 & 2.6 & 0 & 1 & 5 & 20 & 1 & 211.5 \\
\hline 169 & 192 & 0.5 & 0 & 0 & 1 & 5 & 20 & 1 & 29.2 \\
\hline 192 & 193 & 1 & 2.7 & 0 & $\infty$ & 5 & 20 & 1 & 216.4 \\
\hline 170 & 193 & 1 & 0 & 0 & 1 & 5 & 20 & 1 & 27.1 \\
\hline 193 & 194 & 1 & 2.6 & 0 & 1 & 5 & 20 & 1 & 200 \\
\hline 171 & 194 & 1 & 0 & 0 & 1 & 5 & 20 & 1 & 28.4 \\
\hline 194 & 195 & 1 & 2.7 & 0 & 1 & 5 & 20 & 1 & 174.2 \\
\hline 195 & 172 & 1 & 0 & 0 & 1 & 5 & 20 & 1 & 29.1 \\
\hline 195 & 196 & 1 & 2.7 & 0 & 1 & 6 & 20 & 1 & 195 \\
\hline 196 & 173 & 1 & 0 & 0 & 1 & 6 & 20 & 1 & 30.6 \\
\hline 196 & 197 & 1 & 2.7 & 0 & 1 & 6 & 20 & 1 & 219.3 \\
\hline 174 & 197 & 1 & 0 & 0 & 1 & 6 & 20 & 1 & 29.2 \\
\hline 197 & 198 & 1 & 2.7 & -10 & 1 & 6 & 20 & 1 & 197.3 \\
\hline 198 & 175 & 1 & 0 & -10 & 1 & 6 & 20 & 1 & 33.1 \\
\hline 198 & 179 & 1 & 2.4 & 0 & 1 & 6 & 20 & 1.4 & 74.6 \\
\hline 237 & 68 & 0.5 & 8.5 & 0 & 1 & 6 & 20 & 1.4 & 72 \\
\hline 183 & 238 & 0.5 & 0 & 0 & 1 & 6 & 20 & 1.4 & 77 \\
\hline 166 & 239 & 0.5 & 0.4 & 0 & $\infty$ & 6 & 20 & 1.4 & 101.5 \\
\hline 239 & 238 & 0.5 & 0 & 0 & 1 & 6 & 20 & 1.4 & 86.1 \\
\hline 239 & 240 & 0.5 & 0 & 0 & 1 & 6 & 20 & 1.4 & 112.9 \\
\hline 238 & 240 & 1 & 0 & 0 & 1 & 6 & 20 & 1.4 & 25.1 \\
\hline 240 & 182 & 1 & 0.8 & 0 & 1 & 6 & 20 & 1.4 & 77 \\
\hline 237 & 74 & 1 & 0 & 20 & 1 & 6 & 20 & 1.4 & 40 \\
\hline 241 & 102 & 1 & 0.1 & 0 & 1 & 6 & 20 & 1.4 & 40 \\
\hline
\end{tabular}




\section{References}

[1] L. Yun, "Current safety situation analysis in china," China's Development Observer, vol. 1, no. 3, pp. 33-37, 2005.

[2] State Administration of Work Safety, "The national production safety supervision and administration bureau dispatching statistics 2006-2008," pp. 40-41, 2009.

[3] L. Shuling, "The confirmation of the best route for evading accident under the pit," Journal of LiaoNing Technical University, vol. 18, no. 1, pp. 27-29, 1999.

[4] S. Jia, S. Diange, and J. Zhong'an, “The improvement of Dijkstra algorithm used for choosing the best escape route in mine's emergency response," China Mining Magazine, vol. 14, no. 6, pp. 46-48, 2005.

[5] H. Yunbing, X. Xing, Y. Xu et al., "Improved shortest path algorithm based on mine geographic network model," Coal Science and Technology, vol. 39, no. 2, pp. 103-105, 2011.

[6] Y. Wanqing, D. heng, and H. Jiejun, "Mine safety relief system based on the improved Dijkstra algorithm," Mining Safety \& Environmental Protection, vol. 35, no. 3, pp. 40-44, 2008.

[7] S. E. Jalali and M. Noroozi, "Determination of the optimal escape routes of underground mine networks in emergency cases," Safety Science, vol. 47, no. 8, pp. 1077-1082, 2009.

[8] M. Dorigo, V. Maniezzo, and A. Colorni, "Ant system: optimization by a colony of cooperating agents," IEEE Transactions on Systems, Man, and Cybernetics, Part B, vol. 26, no. 1, pp. 29-41, 1996.

[9] D. Jiping, Mining, Chinese Mining University Press, 2009.

[10] W. Deming, "Selecting the optimum escape routes by a computer during a mine fire," Journal of China University of Mining \& Technology, vol. 23, no. 3, pp. 27-32, 1994.

[11] Y. Liao, Fluid Mechanics, China Railway, Beijing, China, 1987.

[12] Z. Yunming, "Study on safe evacuation with performance-based analytical method in public gathering place," Journal of Safety Science and Technology, vol. 7, no. 10, pp. 70-74, 2011.

[13] P. Thompson and E. Marehant, "A computer model for the evacuation of large building populations," Fire Safety Journal, vol. 24, no. 2, pp. 131-148, 1995.

[14] T. Stützle and H. H. Hoos, "Max-Min Ant system," Future Generation Computer Systems, vol. 16, no. 8, pp. 889-914, 2000. 


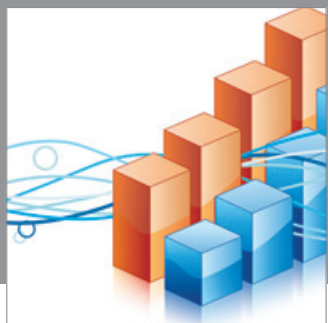

Advances in

Operations Research

mansans

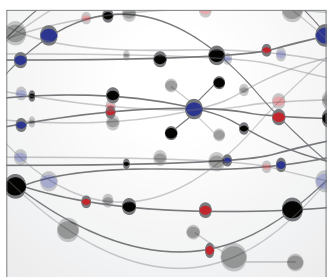

The Scientific World Journal
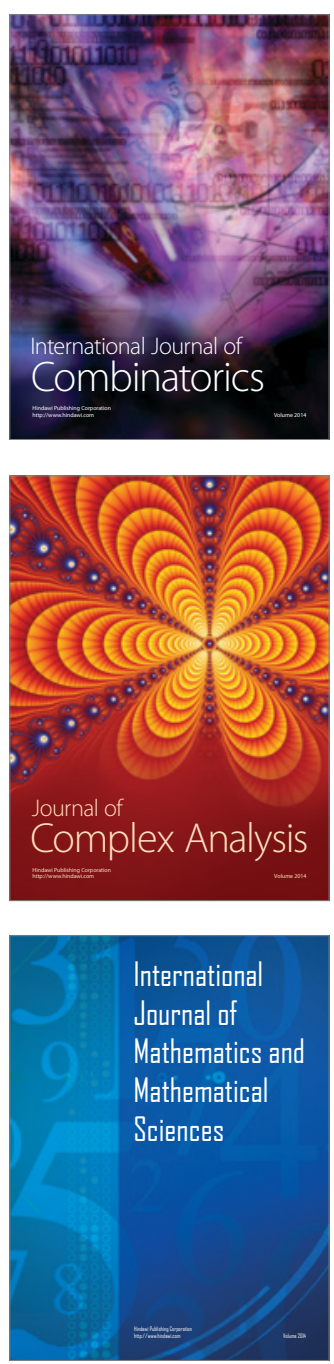
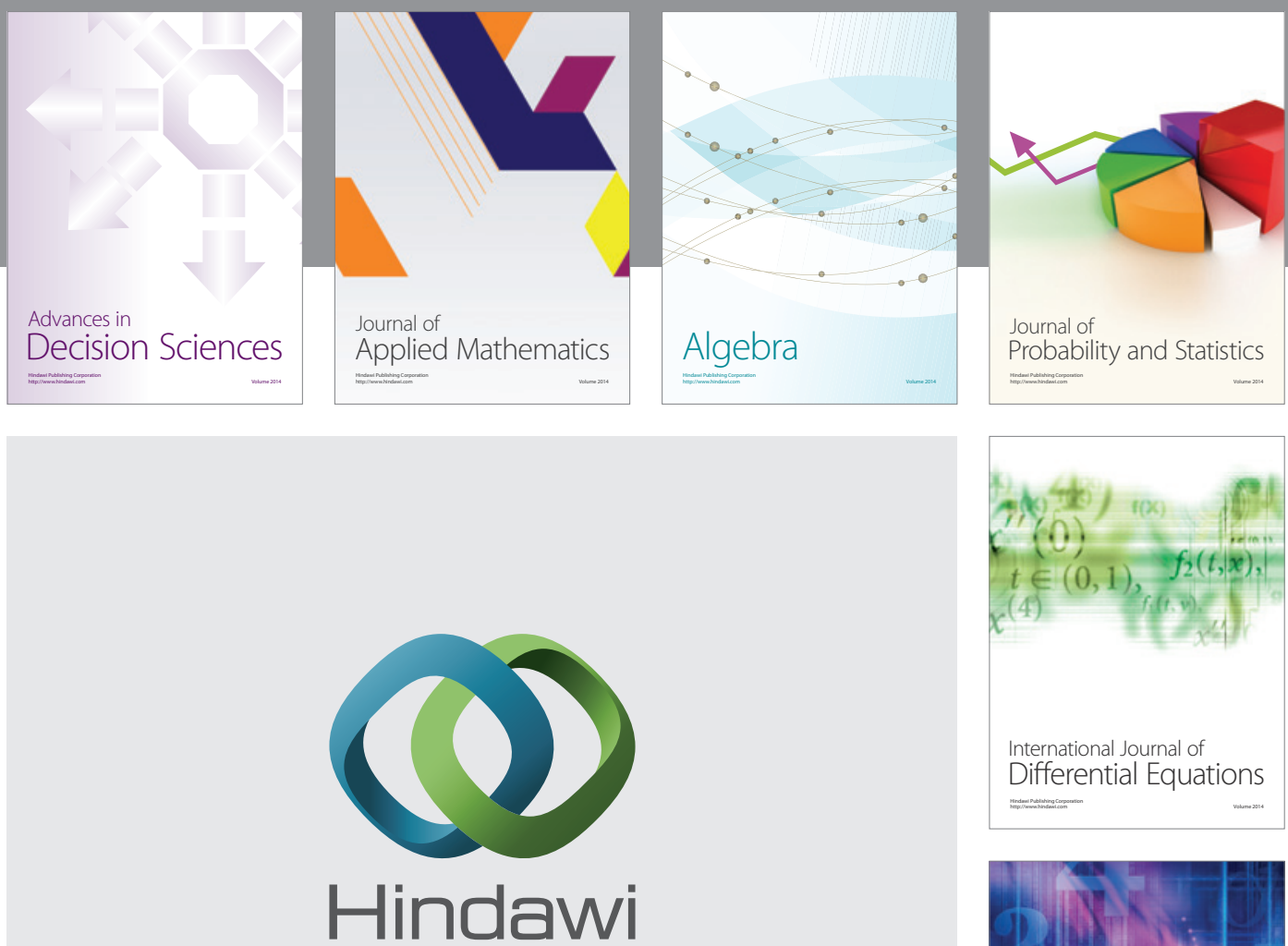

Submit your manuscripts at http://www.hindawi.com
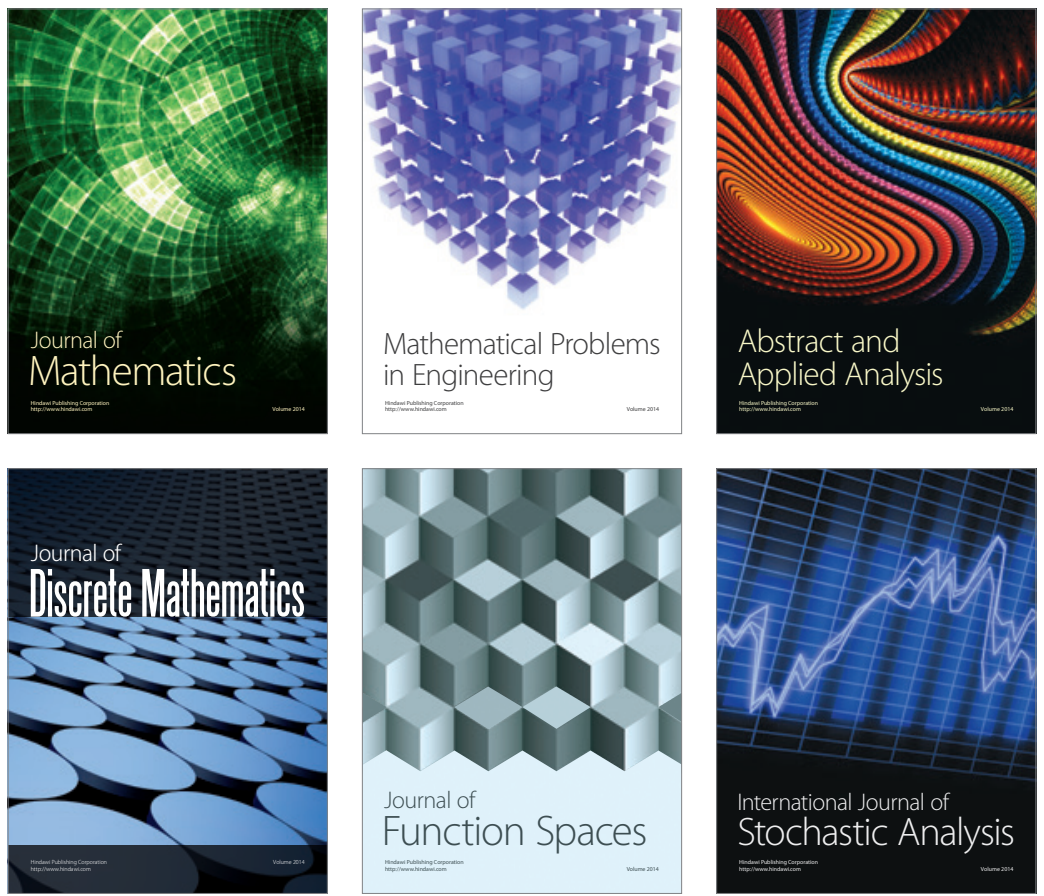

Journal of

Function Spaces

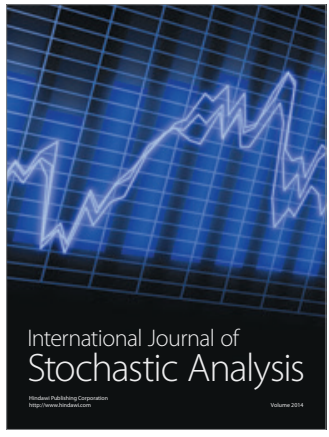

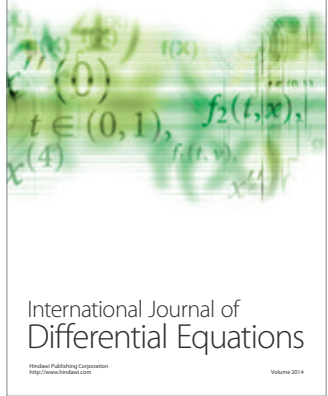
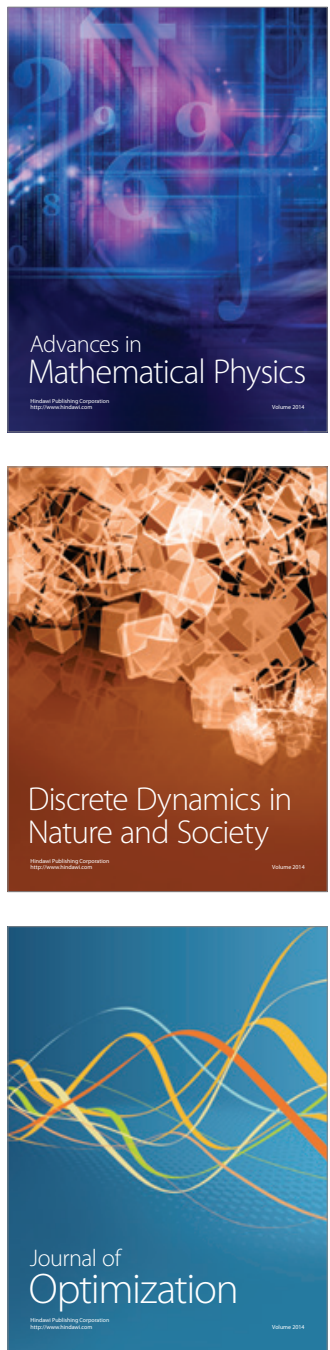